\title{
Management of acute asthma in adults in the emergency department: assisted ventilation
}

\author{
Rick Hodder MD MSc, M. Diane Lougheed MD MSc, J. Mark FitzGerald MD, \\ Brian H. Rowe MD MSc, Alan G. Kaplan MD, R. Andrew Mclvor MD MSc
}

Previously published at www.cmaj.ca

\section{The case}

Jordan, a 32-year-old man with chronic, poorly controlled asthma, has been in the emergency department for 1 hour with only partial response to aggressive bronchodilator therapy and a single intravenous dose of corticosteroids. $\mathrm{He}$ is considered to be at high risk for potentially fatal asthma because of the following clinical features: he is a smoker and has a history of depression; he was admitted to hospital for asthma 8 months previously, and during that stay, 1 day of mechanical ventilation in the intensive care unit was required; his most recent asthma exacerbation occurred 2 months ago; and he has a poor understanding of how to control his asthma and has been relying exclusively on salbutamol for relief of symptoms.

A lthough the prevalence of asthma is increasing, the overall death rate from this disease is falling. In 1995 it was estimated that 400-500 asthma deaths occurred annually in Canada, ${ }^{1}$ but according to the Public Health Agency of Canada, ${ }^{2}$ that figure had dropped by 2004 to 268 deaths among all age groups, a death rate of about 1 per 100000 population. Most asthma exacerbations treated in the emergency department with first-line standard care resolve within 2 hours of presentation. In Canada, only about $6 \%-13 \%$ of patients with asthma exacerbations require admission to hospital, ${ }^{3-5}$ and far fewer require admission to a critical care unit, with or without assisted ventilation. Worldwide, about one-third of patients with acute asthma who are admitted to the intensive care unit (ICU) require mechanical ventilation, and the mortality rate among patients needing mechanical ventilation is about $8 \%(95 \%$ confidence interval $0 \%-38 \%) .{ }^{6}$ Overall, however, the mortality rate from acute asthma exacerbations is low $(<0.1 \%)$, and most deaths occur before arrival at a hospital. There are many potential reasons for death from asthma (Box 1), ${ }^{6-16}$ but a key contributor is a failure on the part of both patients and physicians to appreciate the severity of the exacerbation, which leads to delayed and insufficiently aggressive treatment. ${ }^{10,15}$ In some instances, failure to initiate assisted ventilation in a timely fashion or failure to appropriately manage care during ventilation may contribute to death. ${ }^{11,16,17}$

The pathophysiology of asthma exacerbations has been

\section{Key points}

- Noninvasive ventilation should be used only for selected patients with acute asthma, only in an acute care area and only by experienced personnel.

- A modified rapid-sequence technique should be used for intubation in acute asthma.

- Deep sedation, with doses of opioids sufficient to depress the respiratory drive and occasional use of pharmacologic paralysis, is recommended during the initial period of invasive mechanical ventilation for acute asthma.

- The initial ventilator set-up for acute asthma should minimize the risk of worsening dynamic hyperinflation.

- Initial controlled mechanical hypoventilation allowing "permissive" hypercapnia is recommended for acute, potentially fatal asthma requiring mechanical ventilation.

comprehensively reviewed. ${ }^{6-8}$ In most cases of fatal asthma, autopsy shows narrowing of the airway, extensive plugging with mucus, inflammatory infiltrates, hyperinflation, atelectasis and increased thickness of the airway wall. Acute, severe exacerbations are characterized by obstruction of expiratory airflow and tachypnea. This combination results in trapping of gas because the patient is unable to completely exhale the previous tidal volume before the next breath, which leads in turn to a dynamic increase in end-expiratory lung volume, termed dynamic hyperinflation. Extreme hyperinflation generates high intrathoracic pressure (called intrinsic positive endexpiratory pressure), which can be measured at the end of an exhalation. Hyperinflation and high airway resistance also compromise the efficiency and efficacy of the diaphragm. If not reversed, this problem leads to use of both accessory inspiratory and expiratory muscles in the attempt to maintain ade-

From the Divisions of Pulmonary and Critical Care Medicine (Hodder), University of Ottawa, Ottawa, Ont.; the Division of Respirology, Department of Medicine (Lougheed), Queen's University, Kingston, Ont.; the Division of Respiratory Medicine (FitzGerald), University of British Columbia, Vancouver, BC; the Department of Emergency Medicine and School of Public Health (Rowe), University of Alberta, Edmonton, Alta.; the Department of Family and Community Medicine (Kaplan), University of Toronto, Toronto, Ont.; the Firestone Institute for Respiratory Health (Mclvor), St. Joseph's Healthcare, Hamilton, Ont.; and the Department of Medicine (Mclvor), McMaster University, Hamilton, Ont.

CMAJ 2009. DOI:10.1503/cmaj.080073 


\section{Box 1: Potential reasons for death from acute asthma}

\section{Disease-related factors}

- Overwhelming airway obstruction ${ }^{6-11}$

- Extreme hyperinflation causing asphyxia ${ }^{9-11}$

- Pulmonary barotrauma (e.g., tension pneumothorax) causing obstructive shock ${ }^{12}$

- Cardiac ischemia, dysrhythmia, heart failure

- Complications of disease (e.g., nosocomial infection, cerebral edema, air embolism)

Factors related to management of asthma

- Failure to achieve best possible asthma control ${ }^{13,14}$ - Overreliance on $\beta_{2}$-adrenergic bronchodilators Underutilization of inhaled corticosteroids Poor control of exposure to allergens, irritants and workplace triggers

- Failure of patient to seek early attention for asthma exacerbation ${ }^{10,15}$

- Failure of physician to recognize potential life-threatening exacerbation and to treat aggressively ${ }^{10,15,16}$

- Lack of systematic, guideline-based therapy in the emergency department or hospital ward

quate minute ventilation. Together, these increased inspiratory and expiratory resistive and elastic loads increase the work of breathing. Fatigue of the respiratory muscles may ensue, resulting in an inability to maintain adequate alveolar ventilation, thus leading to hypercapnia and dangerous hypoxemia.

In this article, we present the Canadian Thoracic Society's updated evidence-based key messages for ventilatory management of acute asthma. Recommendations for the nonventilatory management of acute asthma were addressed in a separate article in this series. ${ }^{18}$

These guidelines are intended primarily for emergency physicians and for family physicians who may occasionally care for patients with acute, potentially fatal asthma. Most physicians who initiate assisted ventilation in this setting will have assistance from a respiratory therapist or another physician knowledgeable about ventilatory technique, but even those who only infrequently perform this task should be familiar with the basic principles. A brief review of these principles and associated terminology is provided in Appendix 1 (available at www.cmaj.ca/cgi/content/full/cmaj.080073/DC1). Several excellent reviews on the modern management of acute asthma, including aspects of mechanical ventilation, are also available..$^{6,19-23}$

\section{Sources of information}

In collating evidence for this update, we performed a comprehensive PubMed search using the following search criteria: "asthma," "status asthmaticus," "near fatal asthma," "acute disease," "humans," "adults," "all dates," “all languages," "respiration artificial, mechanical, or invasive, or noninvasive, or bilevel, or positive pressure, or pressure support, or assisted, or volume-control, or pressure-control ventilation," and "NPPV or NIPPV or NIV." In addition, we used the same criteria to search the database of the Cochrane Airways Group. We found no randomized controlled trials comparing invasive mechanical ventilation with no ventilation and only 2 acceptable randomized controlled trials comparing noninvasive positive-pressure ventilation with standard care. In addition, we searched for review articles in the Cochrane database of systematic reviews and the MEDLINE, EMBASE and CINAHL databases using the search criteria "acute severe asthma," "life-threatening asthma near fatal asthma and status asthmaticus," "English," "adults" and "1998-2009." We searched the bibliographies of all identified reviews for additional relevant publications. We also reviewed 3 recent evidence-based guidelines (the Global Initiative for Asthma, ${ }^{24}$ the British Guideline on the Management of Asthma, ${ }^{25}$ and the report of a joint task force of the American Academy of Asthma, Allergy and Immunology, the American Academy of Emergency Medicine and the American Thoracic Society $^{26}$ ) and their respective bibliographies. At least 2 members of the Canadian Thoracic Society Asthma Committee who were also authors of the current report verified relevant references and assigned the recommendation grades and levels of evidence.

We based our grades of evidence on those of the Canadian Task Force on Preventive Health Care,${ }^{27}$ as detailed in a previous article in this series. ${ }^{28}$ Because of the difficulty of conducting randomized controlled trials of potentially fatal asthma, some of the key messages presented later in this article represent only grade I recommendations based on level II-3 or level III evidence. ${ }^{27}$

There is a paucity of high-grade evidence to support specific approaches to the clinical problem of assisted ventilation for acute asthma, and specialists and intensivists experienced with this problem may therefore differ in their preferred management strategies. Nevertheless, we have attempted to formulate recommendations that are straightforward and pragmatic and that will be applicable to the majority of patients with acute, potentially fatal asthma who require some form of assisted ventilation. Referral or transfer to a specialist experienced with assisted ventilation is recommended whenever there is uncertainty about the best course of action, or if the patient's condition remains unstable or there is a lack of response to therapy.

Management of assisted ventilation for potentially fatal asthma in the emergency department has received relatively little attention in national and international guidelines..$^{24-26,29,30}$ Most of the key messages on this topic in the 1996 guidelines of the Canadian Association of Emergency Physicians and the Canadian Thoracic Society ${ }^{29}$ and the 1999 Canadian Asthma Consensus Guidelines ${ }^{30,31}$ remain unchanged and the current recommendations either extend or do not differ substantially from other recently published national ${ }^{25,26}$ and international ${ }^{24}$ guidelines. Additional information on this topic can be found in the emergency department asthma care pathway of the Asthma Plan of Action developed by the Ontario Ministry of Health and Long-Term Care, ${ }^{32}$ which has been endorsed by the Canadian Association of Emergency Physicians and the Canadian Thoracic Society (also available as an online appendix to an earlier article in this series ${ }^{18}$ ). 
Box 2: Indications for transferring a patient with acute asthma to a closely monitored setting or intensive care unit*

- Lack of response to initial aggressive management of acute asthma

- History of risk factors for potentially fatal asthma

- Deterioration of peak expiratory flow or forced expiratory volume in 1 second

- Inability to measure peak expiratory flow or perform spirometry

- Inability to maintain oxygen saturation above $92 \%$

- Persistent distress and rising $\mathrm{PCO}_{2}$

- Development of fatigue

Note: $\mathrm{PCO}_{2}=$ partial pressure of carbon dioxide.

*Level II-3 or level III evidence.

\section{Initial management}

Safe and effective care of a patient with potentially fatal asthma needing assisted ventilation in the emergency department requires rapid access to facilities and personnel experienced in delivering this form of therapy or in providing initial stabilization before transfer to a more suitable facility for this type of care. Treating patients in the emergency setting requires skills in crisis resource management, including good communication, delegation of tasks and frequent reevaluation and reassessment of the patient. ${ }^{33}$

For most patients, initial assessment and management in the emergency department, as described in a previous article in this series ${ }^{18}$ will be sufficient to resolve the crisis. Patients with a lack of response to initial appropriately aggressive therapy and those whose condition is deteriorating have potentially fatal asthma and should be immediately triaged to a closely monitored setting within the emergency department or to a local ICU, if available (Box 2). A secure and reliable intravenous line should be inserted, and oxygenation should be continuously assessed and recorded by pulse oximetry. Supplemental oxygen and aggressive bronchodilator therapy should be continued, and an intravenous dose of corticosteroid should be given, if this has not already been done. ${ }^{34}$

For the patient with no response to initial management, the most important decision is whether some form of assisted ventilation will be required, either noninvasive ventilation by mask (Box 3) or intubation and invasive mechanical ventilation (Box 4).

\section{The case continued}

Following 3 additional cycles of salbutamol plus ipratropium bromide by continuous nebulization, the patient remains in obvious breathing distress, with oxygen saturation $88 \%$ on a $100 \%$ non-rebreather mask. His level of consciousness begins to deteriorate as he becomes exhausted and somnolent from the high work of breathing. Repeat measurement of peak expiratory flow or forced expiratory volume in 1 second $\left(\mathrm{FEV}_{1}\right)$ is not possible because of his distress, and repeat venous blood gas analysis reveals $\mathrm{pH}$ of 7.23 and partial pressure of carbon dioxide $\left(\mathrm{PCO}_{2}\right)$ of $60 \mathrm{~mm} \mathrm{Hg}$. The local 4-bed
Box 3: Characteristics of patients with acute asthma who may be suitable candidates for trial of noninvasive ventilation*

- Clinical judgment suggesting that asthma is likely to respond to treatment in a few hours or less

- High work of breathing

- Breathing rate $>30$ breaths/minute

- Use of accessory muscles of breathing

- Obvious dyspnea

- Progressive fatigue

- Patient alert, cooperative

- Patient able to perform spirometry or peak expiratory flow measurement (level I evidence)

- Oxygen saturation $>90 \%$ on room air (level I evidence)

- $\mathrm{PCO}_{2}<45 \mathrm{~mm} \mathrm{Hg}$ (level I evidence)

- No excessive coughing or phlegm

- No vomiting

- Hemodynamic stability

Note: $\mathrm{PCO}_{2}=$ partial pressure of carbon dioxide.

*Level II-3 or level III evidence, unless specified otherwise.

ICU is full, and a decision is made to transfer him to a regional tertiary care hospital. Because it will take several hours to free up an ICU bed, the patient's immediate care remains the responsibility of the team in the local emergency department. The receiving intensivist discusses the initial management plan with the emergency physician and agrees to remain available by telephone for advice should the need arise during the period preceding the transfer.

The respiratory therapist on duty wonders whether a trial of noninvasive ventilation by mask should be started, as a potential means of avoiding intubation and invasive mechanical ventilation.

\section{Noninvasive ventilation}

Noninvasive ventilation for acute disease is best delivered using a tight-fitting, full-face mask. In general, noninvasive ventilation has several potential advantages over intubation and invasive mechanical ventilation: there is less need for sedation, the patient is free to talk, ventilation can be temporarily suspended to allow the patient to take sips of fluid or to cough and expectorate, and there is a lower risk of ventilator-associated pneumonia. ${ }^{35,36}$ However, although noninvasive ventilation is a promising modality, its routine use cannot currently be recommended. Published anecdotal experience documenting the use of noninvasive ventilation for adults with acute asthma is limited, ${ }^{37-39}$ and only 2 small randomized controlled trials have supported its use in this setting..$^{40,41}$ Until large randomized controlled trials are completed, noninvasive ventilation in acute asthma should be restricted to highly selected cases. It should be used only under close monitoring or in an ICU and only by experienced clinicians backed up by expert respiratory therapy support.

No evidence-based guidelines are available on the selection of patients with acute asthma for whom noninvasive ven- 
Box 4: Clinical observations indicating probable need for elective intubation and mechanical ventilation in acute asthma*

- Exhaustion

- Decreasing level of consciousness

- Drowsiness

- Confusion

Unresponsiveness

- Signs of respiratory muscle fatigue

- Weak breathing efforts

- Silent chest

- Onset of hypercapnia

- Progressive or refractory acidemia $(\mathrm{pH}<7.10)$

- Inability to maintain oxygenation by mask (oxygen saturation $<90 \%$ )

- Cyanosis

- Cardiac instability

- Severe hypotension

Severe cardiac dysrhythmia or ischemia

*Level II-3 or level III evidence.

tilation may be suitable. The patients most likely to benefit are those who are becoming fatigued because of the high work of breathing, but whose condition remains relatively stable and whose asthma is expected to respond to aggressive therapy within a few hours or less (Box 3). In the controlled trials showing success with noninvasive ventilation for acute asthma, the patients had significant airflow obstruction $\left(\mathrm{FEV}_{1}\right.$ $<60 \%$ predicted) but did not have hypercapnia. These patients also had good oxygenation (oxygen saturation $>90 \%$ on room air) and were alert, cooperative and able to perform spirometry.

Bronchodilators can be administered during brief periods when the noninvasive ventilation is interrupted and the mask is removed, or by introducing either a nebulizer or a metereddose inhaler into the ventilation circuit. ${ }^{42-45}$ The dosing of bronchodilators should be empiric and titrated to simple clinical outcomes such as slower, more comfortable breathing. As with patients with acute asthma who are not receiving assisted ventilation, the presence or absence of wheezing is poorly correlated with objectively measured airflow obstruction. ${ }^{46}$ The presence or absence of wheezing should not be used to titrate the dose of bronchodilator.

The main goal of noninvasive ventilation for acute asthma is to avoid the need for intubation and invasive ventilation by reducing the load on the respiratory muscles, thus allowing the patient to rest and buying time for other aspects of therapy to have an effect. Accordingly, if the patient does not visibly relax within 15-30 minutes in response to the noninvasive ventilation, the set-up and technique should be reassessed to ensure correct use. If the set-up is appropriate but the patient is still in distress, judicious sedation with short-acting opiates and sedatives may be considered and the patient assessed for possible intubation and invasive ventilation. In most cases of respiratory failure complicating acute asthma, the safest approach is to administer sedation, intubate and start invasive mechanical ventilation. In circumstances where intubation is not possible or is unavoidably delayed, noninvasive ventilation may be continued to help correct dangerous hypoxemia and extreme acidemia while definitive support is being arranged. Additional details concerning this and other practical aspects of noninvasive ventilation for acute asthma can be found in Appendix 1 (available at www.cmaj.ca/cgi/content /full/cmaj.080073/DC1).

\section{The case continued}

The clinicians feel that the patient's condition is too unstable for a trial of noninvasive ventilation, and they decide to perform elective endotracheal intubation for invasive mechanical ventilation. Intubation is performed by a modified rapid sequence intubation technique, including pharmacologic paralysis, without provoking hypotension, and mechanical ventilation is begun.

\section{Intubation for acute asthma}

Mechanical ventilation is not an ideal therapy for potentially fatal asthma. Because serious complications may occur in association with intubation and positive pressure ventilation, all efforts should be made to avoid unnecessary intubation in this setting. The decision to intubate in asthma is more an art than a science and ideally should be made electively, before the patient suffers catastrophic respiratory collapse.

Decreasing level of consciousness and signs of diaphragmatic fatigue, such as dyscoordination between the abdomen and thorax (i.e., the abdominal wall moves inward during inspiration), suggest that the diaphragm and the patient more generally are becoming exhausted and unlikely to improve rapidly. There is no evidence to support a specific $\mathrm{pH}$ or $\mathrm{PCO}_{2}$ as a trigger for intubation, and worrisome initial blood gas levels often improve substantially in response to first-line therapy for acute asthma. ${ }^{9,47}$ Certain clinical criteria suggest instability and failure to respond to initial therapy (Box 4). Patients meeting these criteria should be considered for immediate intubation.

Endotracheal intubation of a patient with acute asthma who is exhibiting agitation and whose clinical condition is unstable can be difficult. Associated complications include hypotension and heightened risk of gastric aspiration caused by distension of the stomach because of swallowed air, either pre-existing or from bag-and-mask ventilation. Expert help from an anesthetist, intensivist or other physician skilled at intubation in this setting should be called for immediately. If such help is not available, rapid-sequence intubation is recommended $^{32}$ (Appendix 2, available at www.cmaj.ca/cgi /content/full/cmaj.080073/DC1).

\section{Invasive mechanical ventilation}

Patients with asthma who require assisted ventilation fall into 2 main groups: those who are exhausted but still have moderately preserved lung function and those who are exhausted and have extreme degrees of airway obstruction and hyperinflation that will make mechanical ventilation difficult. 
Patients in the first group simply need rest and can usually undergo ventilation without too much difficulty. Ventilating patients in the second group, however, may require input from an intensivist or other experienced individual; transfer to another institution may be necessary. Adopting a ventilatory strategy that will prevent or help to reverse severe dynamic hyperinflation may reduce excessive morbidity and the high mortality rate associated with mechanical ventilation for acute asthma, although the greatest benefits will come from appropriate treatment of the underlying airway obstruction. ${ }^{48-58}$ The basic principles of mechanical ventilation for acute asthma and suggestions for initial ventilator set-up are listed in Box 5. Additional practical details about mechanical ventilation for acute asthma are available in Appendix 1.

In a patient with acute asthma who has undergone intubation, inadequate sedation is a common reason for excessive rates of spontaneous breathing that could worsen hyperinflation and heighten the risk of barotrauma, severe hypotension and cardiovascular collapse. Appropriate sedation to temporarily blunt the patient's drive to breathe is usually needed initially, to ensure the patient's comfort and safety and to maintain synchrony between patient and ventilator. Intravenously administered opiates or propofol ${ }^{59}$ is suitable for this purpose, but vigilance for drug-induced hypotension is necessary. Occasionally, sedation alone is inadequate and consideration must be given to a period of pharmacologic paralysis to achieve safe and effective mechanical ventilation.

Ventilation strategies yielding low tidal volume and low respiratory rates are recommended to minimize the risk of new or worsening dynamic hyperinflation ${ }^{51-53}$ (Box 5), but these are frequently associated with development or persistence of modest hypercapnia. Initially, it may not be possible to raise alveolar ventilation sufficiently to lower the $\mathrm{PCO}_{2}$ without substantially worsening dynamic hyperinflation and causing dangerously high inflation pressures and hypotension through an increase in intrathoracic pressure. ${ }^{12}$ Therefore, it is often safest to accept a $\mathrm{PCO}_{2}$ that is higher than normal and to control arterial or venous $\mathrm{pH}$ with intravenously administered bicarbonate if necessary $(\mathrm{pH}$ above 7.10 being a reasonable initial goal). This approach, called controlled mechanical hypoventilation or permissive hypercapnia, has reduced the high mortality rate previously reported for patients with asthma undergoing ventilation. . $^{51,52,60,61}$ As the patient's fatigue, bronchospasm, mucosal edema and airway plugging gradually resolve in response to bronchodilators and corticosteroids, minute ventilation will increase naturally, and $\mathrm{PCO}_{2}$ and respiratory acidosis will improve. These changes indicate that weaning from mechanical ventilation may soon be possible.

During invasive ventilation, bronchodilators can be administered by either wet nebulization or metered-dose inhaler with a holding chamber or spacer. ${ }^{62}$ The effects of turbulent flow dictate that if a metered-dose inhaler and spacer combination is used, multiple puffs (usually 4-8) timed with the patient's inspiration should be administered individually ${ }^{62-64}$ The dosing of bronchodilators should be empiric and should be titrated to simple outcomes such as reduction of air-trapping, increase in exhaled tidal volumes (Appendix 1) and, for patients who are breathing spontaneously, slower, more comfortable breathing.
Box 5: Principles of initial mechanical ventilation for acute, potentially fatal asthma

1. Attempt to maintain oxygen saturation $\geq 92 \%$ (use $100 \%$ oxygen initially)

2. Have patience with the process of reducing $\mathrm{PCO}_{2}$

- Keep pH > 7.10 (give bicarbonate intravenously as needed)

3. Minimize dynamic hyperinflation:

- Modest rate of assisted ventilation (8-12 breaths/minute)

- Low to normal tidal volume (6-8 mL/kg)

- Inspiratory flow rate $>60 \mathrm{~L} / \mathrm{min}$ or inspiratory time $\leq 1-1.5$ second

- Peak inflation pressure $<50 \mathrm{~cm} \mathrm{H}_{2} \mathrm{O}$

- Plateau pressure $<35 \mathrm{~cm} \mathrm{H} \mathrm{H}_{2} \mathrm{O}$

4. Begin with low applied positive end-expiratory pressure (e.g., 2-5 $\mathrm{cm} \mathrm{H}_{2} \mathrm{O}$ )

5. If necessary, use intravenous opiates to suppress breathing drive and pharmacologic paralysis to prevent dyssynchrony between patient and ventilator

Note: $\mathrm{PCO}_{2}=$ partial pressure of carbon dioxide.

As with patients with acute asthma who are not receiving assisted ventilation, the presence or absence of wheezing is poorly correlated with objectively measured obstruction of airflow; ${ }^{46}$ therefore, the dose of bronchodilator should not be titrated to the presence or absence of wheezing.

\section{The case continued}

Shortly after mechanical ventilation begins, the respiratory therapist notes that the tidal volumes delivered by the ventilator are falling, and soon the ventilator's high-pressure alarm begins to sound. The patient is still asleep, with pharmacologic paralysis caused by the drugs given before intubation. The postintubation chest radiograph shows extreme hyperinflation but no signs of barotrauma (i.e., no pneumothorax and no mediastinal or subcutaneous air) or opacities that might suggest pneumonia.

It is quickly determined that in a misguided attempt to rapidly lower the patient's $\mathrm{PCO}_{2}$ (which had a measured value of $60 \mathrm{~mm} \mathrm{Hg}$ ), the ventilator has been set to deliver tidal volumes of $10 \mathrm{~mL} / \mathrm{kg}$ at a breathing rate of 16 breaths/minute, which has worsened air-trapping and dynamic hyperinflation. The tidal volume is decreased to $7 \mathrm{~mL} / \mathrm{kg}$ and the ventilator rate to 8 breaths/minute. The air-trapping stops, as does the high-pressure alarm, indicating a safer ventilatory pattern.

\section{Adverse effects of mechanical ventilation}

Complications of invasive mechanical ventilation commonly occur, often immediately after intubation. Deterioration soon after intubation, characterized by hypotension, hypoxemia, hemodynamic instability or hypoventilation, may have several potential causes, including the sedative drugs used for intubation; pre-existing depletion of the intravascular volume (dehydration); misplacement of the tube, such as intubation of the right main stem bronchus or esophageal intubation; sudden worsening of a pre-existing but unrecognized pneumo- 
Box 6: Key messages for the management of assisted ventilation for acute, potentially fatal asthma*

\section{Noninvasive ventilation}

- Noninvasive ventilation should be used only for selected patients with acute asthma and only in an acute care area. Ventilation should be initiated only by experienced personnel (grade A recommendation; level I evidence).

\section{Intubation for acute asthma}

- Except in cases of cardiopulmonary collapse, the decision to intubate for acute asthma should be considered only after administration of aggressive anti-inflammatory and bronchodilator therapy.

- The decision to intubate for acute asthma should generally be based on clinical criteria rather than any specific blood gas levels.

- A modified rapid-sequence technique should be used for intubation in acute asthma.

\section{Invasive mechanical ventilation}

- Deep sedation, with doses of opioids sufficient to depress the respiratory drive and occasional use of pharmacologic paralysis, is recommended during the initial period of invasive mechanical ventilation for acute asthma (grade B recommendation; level II-2 evidence).

- The initial ventilator set-up for acute asthma should minimize the risk of worsening dynamic hyperinflation (grade B recommendation; level II-2 evidence).

- Initial controlled mechanical hypoventilation allowing "permissive" hypercapnia is recommended for acute, potentially fatal asthma (grade B recommendation, level II-2 evidence).

- Dyssynchrony between the patient and the ventilator ("fighting the ventilator") should be dealt with initially by disconnecting the ventilator and assisting ventilation with $100 \%$ oxygen administered through a self-inflating bag.

- Hypotension during invasive mechanical ventilation for asthma may necessitate temporary discontinuation of positive-pressure ventilation, to permit exhalation of trapped air and reduction of hyperinflation.

- Sudden or persistent hypotension during mechanical ventilation for asthma requires assessment for possible tension pneumothorax.

Therapy when ventilation is difficult or impossible

- Helium-oxygen or inhalational and/or intravenous anesthetic agents may be considered to permit adequate mechanical ventilation for patients with potentially fatal asthma who require assisted ventilation.

\section{Preventing future need for assisted ventilation}

- Any patient who requires assisted ventilation for asthma should be seen by an asthma specialist before discharge from hospital.

*All grade I recommendations, based on level II-3 or level III evidence, unless indicated otherwise.

thorax coincident with initiation of positive pressure ventilation; substantial worsening of dynamic hyperinflation caused by excessive hand-bagging; or inappropriate set-up of the ventilator.

Without adequate sedation and pharmacologic paralysis, the patient may become agitated and may physically interfere with mechanical ventilation or cause other problems by biting down on or even removing the endotracheal tube. Dyssyn- chrony between the patient and the ventilator ("fighting the ventilator") should be dealt with initially by disconnecting the ventilator and assisting the patient's ventilation by means of a self-inflating bag with $100 \%$ oxygen (Appendix 1).

Patients with acute and potentially fatal asthma experience dynamic hyperinflation because obstruction of the expiratory airflow leads to trapping of air. Hyperinflation can also be made worse when the inspiratory cycle is allowed to begin before the preceding exhalation and expiratory flow have finished. Conditions favouring the development of air-trapping and dynamic hyperinflation include excessively rapid breathing rates (for both spontaneous breathing and machine ventilation) leading to inappropriately short exhalation times, and the setting of too large a tidal volume on the ventilator when there is insufficient time for exhalation. ${ }^{58}$ If the waveform of the expiratory flow can be displayed on the ventilator, the presence of dynamic hyperinflation can be inferred from expiratory flow that persists right up to the onset of the next machine or spontaneous breath (Appendix 1). Dynamic hyperinflation should also be suspected if exhalation sounds are heard (via a stethoscope over the trachea) right up until the next inspiration. ${ }^{65}$ If exhalation has not stopped before the next inspiration starts in a patient who is breathing spontaneously, the adequacy of bronchodilator therapy should be reassessed and additional sedation may be required. If exhalation ends before the next inspiration begins, inducing slower breathing rates will not further reduce the risk of hyperinflation. ${ }^{58}$ Additional details concerning problems during intubation and mechanical ventilation for acute asthma are provided in Appendix 1.

\section{Outcome of the case}

The patient's condition continues to improve, and ventilation is switched to a spontaneous mode consisting of continuous positive airway pressure plus pressure support. The next morning, the sedation is discontinued, and the endotracheal tube is removed.

The patient is referred to a respirologist and an asthma educator to discuss ways to improve overall control of his asthma and to prevent another episode of potentially fatal asthma.

\section{Discontinuation of ventilation}

Most patients with asthma will improve quickly after a period of ventilation and rest, and the endotracheal tube can be removed without a prolonged weaning phase, especially if fatigue was the main problem and the patient's lung mechanics were not too adversely affected. However, if the patient's lung mechanics and $\mathrm{PCO}_{2}$ are slow to improve, weaning can be difficult, and a more gradual process is required, possibly involving consultation with experts.

\section{Follow-up}

Consultation with an asthma specialist is essential for all patients who have had a near-fatal episode of asthma or who have required assisted ventilation for acute asthma, because such situations clearly indicate poor asthma control. Such a 
consultation optimally takes place before the patient is discharged to facilitate patient education, to allow preparation of a written asthma action plan, to optimize anti-inflammatory therapy, to review any barriers to asthma control and to plan and ensure adherence with follow-up appointments.

\section{Gaps in knowledge and care}

The key messages for the ventilatory management of asthma in adults in the emergency department are presented in Box 6 .

Gaps in care and knowledge represent opportunities for future research in assisted ventilation for acute potentially fatal asthma.

A more systematic, evidence-based approach to the management of acute asthma in the emergency department should be promoted. ${ }^{1,5}$ Use of structured management plans or care maps for acute asthma should be included in the criteria for hospital accreditation. Strategies are needed to increase the frequency of use of spirometry and peak expiratory flow in the emergency department. Strategies are also needed to improve early recognition of potentially severe asthma exacerbations to facilitate timely institution of appropriately aggressive therapy, including assisted ventilation. Many of these gaps may be lessened by efforts to improve the dissemination and implementation of asthma guidelines. ${ }^{66}$

There is a need for better research into the possible role of noninvasive ventilation in routine treatment for acute asthma, as well as research into novel ways of applying mechanical ventilation, including self-adjustment based on real-time physiologic and neuronal feedback. Although permissive hypercapnia is well tolerated, more research into the safety of this ventilation strategy is required. Additional research is also needed to determine the most efficient way of administering inhaled bronchodilators during both noninvasive and invasive ventilation.

\section{This article has been peer reviewed.}

Competing interests: Diane Lougheed has served on GlaxoSmithKline's National Respiratory Epidemiology Advisory Board. She has received research grants from AllerGen NCE, Ception Therapeutics, Topigen Pharmaceuticals, the Ontario Ministry of Health and Long-Term Care, the Ontario Thoracic Society and the Queen's University William M. Speare Endowment/Start Memorial Fund. Brian Rowe has received research funding and speaker fees from GlaxoSmithKline and AstraZeneca. He is supported by the 21st Century Canada Research Chairs program through the government of Canada. Mark FitzGerald has served on advisory boards for GlaxoSmithKline, AstraZeneca, Novartis, Pfizer, Boehringer-Ingelheim, Altana, Merck and Topigen. He has also been a member of speakers' bureaus for GlaxoSmithKline, AstraZeneca, Boehringer-Ingelheim, Pfizer and Merck. He has received research funding paid directly to the University of British Columbia from the Canadian Institutes of Health Research, AstraZeneca, GlaxoSmithKline, Boehringer-Ingelheim, Merck, Wyeth, Schering, Genentech and Topigen. Mark FitzGerald is a member of the Global Initiative for Asthma (GINA) and is chair of the GINA Science Committee. Alan Kaplan has received honoraria for talks from AstraZeneca, GlaxoSmithKline, Nycomed, Boehringer-Ingelheim and Pfizer. He has served on advisory boards for Merck Frosst, Nycomed, AstraZeneca and Boehringer-Ingelheim. He has received travel reimbursement to meetings of the European Respiratory Society from Merck and AstraZeneca. Andrew McIvor and Rick Hodder have attended advisory board meetings and provided continuing medical education for which they have received honoraria from pharmaceutical companies involved in asthma management: AstraZeneca, Boehringer-Ingelheim, Graceway, GlaxoSmithKline, Novartis, Merck Frosst and Pfizer.
Contributors: All authors contributed to the development and editing of the publication, and all approved the final version submitted for publication.

Funding: The Canadian Thoracic Society has received funding to facilitate the knowledge translation activities of the CTS Asthma Committee from AstraZeneca Canada, GlaxoSmithKline Inc., Merck Frosst Canada and Novartis Pharmaceuticals. None of the sponsors played a role in the collection, review, analysis or interpretation of the scientific literature or in any decisions regarding the key messages presented in the case studies.

\section{REFERENCES}

1. Hogg R, Schecter M, Montaner J, et al. Asthma mortality in Canada, 1946 to 1990. Can Respir J 1995;2:61-6.

2. Life and breath: respiratory disease in Canada. Ottawa (ON): Public Health Agency of Canada; 2007. Available: www.phac-aspc.gc.ca/publicat/2007/lbrdcvsmrc/index-eng.php (accessed 2009 Sept. 14).

3. Lougheed MD, Garvey N, Chapman K, et al. The Ontario Asthma Regional Variation Study: emergency department visit rates and the relation to hospitalization. Chest 2006;129:909-17.

4. Rowe BH, Bota G, Clark S, et al. Comparison of Canadian versus American emergency department visits for acute asthma. Can Respir J 2007;14:331-7.

5. Lougheed MD, Garvey N, Chapman K, et al. Variations and gaps in management of acute asthma in Ontario emergency departments. Chest 2009;135:724-36.

6. McFadden ER Jr. Acute severe asthma. Am J Respir Crit Care Med 2003;168:740-59.

7. Wark PA, Gibson P. Asthma exacerbations: 3. Pathogenesis. Thorax 2006;61:909-15.

8. Carroll N, Elliot J, Morton A, et al. The structure of large and small airways in nonfatal and fatal asthma. Am Rev Respir Dis 1993;147:405-10.

9. Molfino NA, Slutsky AS. Near-fatal asthma. Eur Respir J 1994;7:981-90.

10. FitzGerald JM, Macklem P. Proceedings of a workshop on near fatal asthma. Can Respir J 1995;2:113-25.

11. FitzGerald JM, Macklem P. Fatal asthma. Annu Rev Med 1996;47:161-8.

12. Marcy TW. Barotrauma: detection, recognition, and management. Chest 1993;104:578-84.

13. Hodder R. The paradox of adult asthma control: "Who's in control anyway?" Can Respir J 2007;14:229-34.

14. Turner M, Crump S, Vedal S, et al. Risk factors for near-fatal asthma: results from a prospective case-control study. Am J Respir Crit Care Med 1998;157:1804-9.

15. Johnson AJ, Nunn A, Somner A, et al. Circumstances of death from asthma. BMJ 1984;288:1870-2.

16. Rea HH, Sears MR, Beaglehole R, et al. Lessons from the national asthma mortality study. N Z Med J 1987;100:10-3.

17. Rothwell RP, Rea H, Sears M, et al. Lessons from the national asthma mortality study: deaths in hospital. N Z Med J 1987;100:199-202.

18. Hodder R, Lougheed MD, Rowe BH, et al. Management of acute asthma in adults in the emergency department: nonventilatory management. CMAJ 2009; 182:E55-67.

19. Stather DR, Stewart TE. Clinical review: mechanical ventilation in severe asthma Crit Care 2005;9:581-7.

20. Phipps P, Garrard CS. The pulmonary physician in critical care 12: acute severe asthma in the intensive care unit. Thorax 2003;58:81-8.

21. Oddo M, Feihl F, Schaller M, et al. Management of mechanical ventilation in acute severe asthma: practical aspects. Intensive Care Med 2006;32:501-10.

22. Williams TJ, Tuxen DV, Scheinkestel CD, et al. Risk factors for morbidity in mechanically ventilated patients with acute severe asthma. Am Rev Respir Dis 1992;146:607-15.

23. Medoff BD. Invasive and noninvasive ventilation in patients with asthma. Respir Care 2008;53:740-8

24. Global strategy for asthma management and prevention. Global Initiative for Asthma; 2008. Available: www.ginasthma.org/Guidelineitem.asp??11=2\& 12=1\&intId=1561 (accessed 2009 Sept. 29).

25. British Thoracic Society; Scottish Intercollegiate Guidelines Network. British guideline on the management of asthma: a national clinical guideline. London (UK): The Society; 2008 [revised 2009]. Available: www.sign.ac.uk/pdf /sign101.pdf (accessed 2009 Sept. 29).

26. Schatz M, Kazzi A, Brenner B, et al. Joint task force report: supplemental recommendations for the management and follow-up of asthma exacerbations. Proc Am Thorac Soc 2009;6:353-93.

27. Canadian Task Force on Preventive Healthcare. New grades for recommendations from the Canadian Task Force on Preventive Healthcare. CMAJ 2003;169:207-8.

28. Kaplan A, Balter M, Bell A, et al. Diagnosis of asthma in adults. CMAJ 2009;181 E210-20.

29. Beveridge RC, Grunfeld AF, Hodder RV, et al. Guidelines for the emergency management of asthma in adults. CAEP/CTS Asthma Advisory Committee. Canadian Association of Emergency Physicians and Canadian Thoracic Society. CMAJ 1996;155:25-37.

30. Boulet LP, Becker A, Bérubé D, et al. Canadian asthma consensus report, 1999. Canadian Asthma Consensus Group. CMAJ 1999;16(Suppl 11):S1-61.

31. Boulet LP, Bai T, Becker A, et al. What is new since the last (1999) Canadian Asthma Consensus Guidelines? Can Respir J 2001;8(Suppl A):5A-27A.

32. Emergency department asthma care pathway. Toronto (ON): Ontario Lung Association, Ministry of Health and Long-Term Care; 2009. Available: www.on.lung.ca 
/Health-Care-Professionals/EDACP/emerg_path_dl.php (accessed 2009 Sep. 20).

33. Schull MJ, Ferris LE, Tu J, et al. Problems for clinical judgement 3. Thinking clearly in an emergency. CMAJ 2001;164:1170-5.

34. Rowe BH, Spooner C, Ducharme F, et al. Early emergency department treatment of acute asthma with systemic corticosteroids [review]. Cochrane Database Syst Rev 2001;(1):CD002178.

35. British Thoracic Society Standards of Care Committee. BTS guideline: non-invasive ventilation in acute respiratory failure. Thorax 2002;57:192-211.

36. Mehta S, Hill NS. Noninvasive ventilation. Am J Respir Crit Care Med 2001;163:540-77.

37. Meduri GU, Cook TR, Turner RE, et al. Noninvasive positive pressure ventilation in status asthmaticus. Chest 1996;110:767-74.

38. Fernandez MM, Villagra A, Blanch L, et al. Non-invasive mechanical ventilation in status asthmaticus. Intensive Care Med 2001;27:486-92.

39. Ram F, Wellington S, Rowe B, et al. Non-invasive positive pressure ventilation for treatment of respiratory failure due to severe acute exacerbations of asthma [review]. Cochrane Database Syst Rev 2005;(3):CD004360.

40. Soroksky A, Stav D, Shpirer I. A pilot prospective, randomized, placebo-controlled trial of bilevel positive airway pressure in acute asthmatic attack. Chest 2003; 123:1018-25.

41. Soma T, Hino M, Kida K, et al. A prospective and randomised study for improvement of acute asthma by non-invasive positive pressure ventilation (NPPV). Intern Med 2008;47:493-501.

42. Dhand R. Aerosol bronchodilator therapy during non-invasive positive pressure ventilation: a peek through the looking glass. Respir Care 2005;50:1621-2.

43. Branconnier MP, Hess D. Aerosol delivery during non-invasive ventilation. Respir Care 2005;50:1649-1653.

44. Chatmongkolchart S, Schettino GP, Dillman C, et al. In vitro evaluation of aerosol bronchodilator delivery during noninvasive positive pressure ventilation: effect of ventilator settings and nebulizer position. Crit Care Med 2002;30:2515-9.

45. Nava S, Karakurt S, Rampulla C, et al. Salbutamol delivery during non-invasive mechanical ventilation in patients with chronic obstructive pulmonary disease: a randomized controlled study. Intensive Care Med 2001;27:1627-35.

46. Shim C, Williams M. Relationship of wheezing to the severity of obstruction in asthma. Arch Intern Med 1983;143:890-2.

47. Mountain RD, Sahn S. Clinical features and outcome in patients with acute asthma presenting with hypercapnia. Am Rev Respir Dis 1988;138:535-9.

48. Corbridge TC, Hall JB. The assessment and management of adults with status asthmaticus. Am J Respir Crit Care Med 1995;151:1296-316.

49. Ranieri VM, Giuliani R, Cinnella G, et al. Physiologic effects of positive end-expiratory pressure in patients with chronic obstructive pulmonary disease during acute ventilatory failure and controlled mechanical ventilation. Am Rev Respir Dis 1993;147:5-13.

50. Branthwaite MA. An update on mechanical ventilation for severe acute asthma Clin Intensive Care 1990;1:4-6.

51. Darioli R, Perret C. Mechanical controlled hypoventilation in status asthmaticus. Am Rev Respir Dis 1984;129:385-7.

52. Menitove SM, Goldring RM. Combined ventilator and bicarbonate strategy in the management of status asthmaticus. Am J Med 1983;74:898-901

53. Tuxen DV. Permissive hypercapnic ventilation. Am J Respir Crit Care Med 1994;150:870-4

54. Shapiro JM. Intensive care management of status asthmaticus. Chest 2001;120:1439-41.

55. Tuxen DV, Williams TJ, Scheinkestel CD, et al. Use of a measurement of pulmonary hyperinflation to control the level of mechanical ventilation in patients with acute severe asthma. Am Rev Respir Dis 1992;146:1136-42.

56. Dhuper S, Maggiore D, Chung V, et al. Profile of near-fatal asthma in an inner-city hospital. Chest 2003;124:1880-4.

57. Hodder R. Management of the intubated asthmatic. Ont Thorac Soc Rev 1994;6:2-6.

58. Leatherman JW, McArthur C, Shapiro RS. Effect of prolongation of expiratory time on dynamic hyperinflation in mechanically ventilated patients with severe asthma. Crit Care Med 2004;32:1542-5.

59. Conti G, Dell'Utri D, Vilardi V, et al. Propofol induces bronchodilation in mechanically ventilated chronic obstructive pulmonary disease (COPD) patients. Acta Anaesthesiol Scand 1993;37:105-9.
60. Mutlu GM, Factor P, Schwartz DE, et al. Severe status asthmaticus: management with permissive hypercapnia and inhalation anesthesia. Crit Care Med 2002;30:477-80.

61. Mansel JK, Strogner S, Petrini M, et al. Mechanical ventilation in patients with acute severe asthma. Am J Med 1990;89:42-8

62. Dhand R. Basic techniques for aerosol delivery during mechanical ventilation. Respir Care 2004;49:611-22.

63. Dhand R, Duarte AG, Jubran A, et al. Dose-response to bronchodilator delivered by metered-dose inhaler in ventilator-supported patients. Am J Respir Crit Care Med 1996;154:388-93.

64. Dhand R. Maximizing aerosol delivery during mechanical ventilation: go with the flow and go slow. Intensive Care Med 2003;29:1041-2.

65. Kress JP, O'Connor M, Schmidt G. Clinical examination reliably detects intrinsic positive end-expiratory pressure in mechanically ventilated patients. Am J Respir Crit Care Med 1999;159:290-4

66. Boulet LP, Becker A, Bowie D et al. Implementing practice guidelines: a workshop on dissemination and implementation with a focus on asthma and COPD. Can Respir J 2006;(Suppl A):5A-47A.

Correspondence to: Dr. Rick Hodder, Divisions of Pulmonary and Critical Care Medicine, The Ottawa Hospital - Civic Campus, Ottawa ON K1Y4E9; rhodder@ottawahospital.on.ca

This article is the sixth in a 7-part case study series that was developed as a knowledge translation initiative of the Canadian Thoracic Society Asthma Committee. The series aims to educate and inform primary care providers and nonrespiratory specialists about the diagnosis and management of asthma. The key messages presented in the cases are not clinical practice guidelines but are based on a review of the most recent scientific evidence available. Financial support for the publication of this series has been provided, in part, by the Canadian Thoracic Society.

\section{Articles to date in this series}

- Subbarao P, Mandhane PJ, Sears MR. Asthma: epidemiology, etiology and risk factors. CMAJ 2009. DOI:10.1503/cmaj.080612

- Kaplan AG, Balter MS, Bell AD, et al. Diagnosis of asthma in adults. CMAJ 2009. DOI:10.1503/cmaj.080006.

- Balter MS, Bell AD, Kaplan AG, et al. Management of asthma in adults. CMAJ 2009. DOI:10.1503/cmaj.080007.

- Chapman KR, Mclvor RA. Asthma unresponsive to usual care. CMAJ 2009. DOI:10.1503/cmaj.090089.

- Hodder R, Lougheed D, Rowe BH et al. Management of acute asthma in adults in the emergency department: nonventilatory management. CMAJ 2009.

DOI:10.1503/cmaj.080072 